\title{
LA RESPONSABILIDAD CIVIL DE LOS ADMINISTRADORES DE LA COPROPIEDAD. ¿SOLOS ANTE INMINENTES PELIGROS? ${ }^{1}$
}

Vladimir Monsalve Caballero. Abogado, Especialista en Derecho comercial y financiero, Máster Oficial en Regulación Económica de la Universidad de Salamanca, Doctor sobresaliente cum laude en Derecho de la Universidad de Salamanca. Profesor investigador y miembro del grupo de investigación en Derecho y Ciencia Política de la facultad de Derecho de la Universidad del Norte de Barranquilla, para contactar: vmonsalve@uninorte.edu.co

Fecha de entrega: Septiembre 14 de 2009

Fecha de Aprobación: Noviembre 23 de 2009

\section{Resumen:}

El artículo pretende hacer un análisis sobre cuáles son los eximentes de responsabilidad que tienen los administradores de las copropiedades, frente a la imputación de daños producidos en accidentes sufridos por visitantes, residentes y copropietarios al interior de los bienes comunes, de acuerdo a lo reglamentado en el artículo 50 de la ley 675 de 2001, donde se estable que el régimen legal por aplicar es el de responsabilidad subjetiva por culpa presunta.

Palabras clave: Responsabilidad objetiva, propiedad horizontal, eximentes de responsabilidad, daños.

\section{Abstract:}

These paper pretends to make an analysis about the field of excluding responsibility causes for the administrators of horizontal properties compared to the allocation of damages in accidents involving visitors, residents and owners within the property, as regulated in Article 50 of Act 675 of 2001, where the stable legal regime to apply the strict liability.

Keywords: strict liability, horizontal property, responsibility excemption, damages.

\footnotetext{
${ }^{1}$ El texto corresponde a la ponencia del mismo nombre presentada en "el 3er seminario del Nororiente Colombiano para administradores y miembros de consejo de administración de los conjuntos residenciales y mixtos", organizado por la firma Monsalve Abogados, celebrado en la cámara de comercio de Bucaramanga el 25 de Noviembre de 2007. El autor agradece al profesor y amigo Luis Carlos Plata López, sus comentarios y precisiones sin las cuales no hubiese sido posible la corrección y revisión del presente trabajo.
} 


\section{REVISTA VIRTUAL VIA INVENIENDI ET IUDICANDI \\ "CAMINO DEL HALLAZGO Y DEL JUICIO" \\ http://viei.usta.edu.co/ E-MAIL: revistainveniendi@usantotomas.edu.co}

\section{Presentación}

Si bien el derecho es una ciencia, que como ninguna otra debe evolucionar y dinamizar su proceso de adaptabilidad a la realidad circundante, en los últimos años ninguna de sus ramas ha sufrido cambios tan radicales y estructurales como la rama del derecho privado, haciendo de ella sin duda, el estandarte reflector de una nueva sociedad donde en la actualidad principios como el neminen leadere (no dañar a nadie), recobran la total vigencia que tuvieron en el antiguo imperio romano y donde el nivel de diligencia exigible a las personas es cada vez mayor, elevando los listones de su prudencia y cuidado cuando se está frente a cargos de manejo, dirección y control, como es la labor que le asiste a los administradores de los bienes sometidos al régimen de propiedad horizontal bajo el actual panorama legal.

Nos enfrentamos a una sociedad, donde el individualismo impera y la antigua distribución del riesgo desaparece. Estamos avocados a un grupo social contractualizado, donde, es el negocio jurídico la máxima expresión de la autonomía privada, y en él se ampara la comunidad como el último recurso para el tráfico de bienes y servicios. El contrato no ha sido ajeno a los cambios sociales y culturales que ha traído la sociedad de mercado y de consumo. De tal forma que aquel que contrata, hoy día es un experto que conoce no solo la materia objeto de regulación, sino las circunstancias sociales, económicas y hasta familiares que se ven perfectamente acopladas en la copropiedad ${ }^{2}$.

La actual legislación ha hecho exigible con más ahínco los conceptos de culpa, diligencia y experticia, edificando estándares de comportamiento diferentes al histórico padre de familia aplicable a los contratos consagrados en el Código civil ${ }^{3}$. En materia de responsabilidad civil, son múltiples los fallos y sentencias emanados de los diferentes despachos judiciales, donde se hace especial empeño sobre la labor que ejercen los representantes legales de las personas jurídicas, y donde se hace especial énfasis al ejercicio de la actividad de una forma profesional, cuyas personas deben ser idóneas, previsivas, cautelosas, y sobre todo diligentes ${ }^{4}$.

\footnotetext{
${ }^{2}$ Vale la pena resaltar en todo caso que la copropiedad más que de un contrato nace como de un contrato o cuasicontrato, que es el de comunidad, esto por la falta de consenso entre los copropietarios para conformar la misma o convivir en ella.

${ }^{3}$ Auspiciado lo anterior, por la defectuosa construcción legal que tiene el ordenamiento civil en el ámbito de la culpa en vías contractuales y su diferentes graduaciones. Par ver el artículo 1604 que contiene la clásica tridivisión de la culpa en culpa grave, leve y levisima1604 C.C. y el art. 2155 el cual contiene una defectuosa redacción y deja entrever que dentro de la responsabilidad del mandatario, la clasificación de la culpa leve tiene dos categorías más. Situación sobre la que no nos detendremos por no ser el objeto principal de la presente intervención, no obstante es un tema relevante en la medida que es el contrato de mandato el vínculo jurídico que es más utilizado en la relación copropiedad- administrador.

${ }^{4}$ Corte Constitucional mediante sentencia C-318 de mayo 2 de 2002. M.P. Alfredo Tulio Beltrán Sierra, Sentencia T-143 febrero 22 de 2000. M.P. Antonio Barrera Carbonell, Sentencia T-468 de mayo 13 de 2004 M.P. Gerardo Monroy Cabra.
} 


\section{REVISTA VIRTUAL VIA INVENIENDI ET IUDICANDI \\ "CAMINO DEL HALLAZGO Y DEL JUICIO" \\ http://viei.usta.edu.co/ E-MAIL: revistainveniendi@usantotomas.edu.co}

Desde la promulgación de la nueva ley de propiedad horizontal, se ha debatido y discutido, diferentes ámbitos teniendo especial énfasis en lo que le incumbe directamente a los propietarios y residentes, cuotas sociales, expensas comunes, responsabilidad de los constructores entre otros, dejando siempre de un lado, el tema que hoy día nos proponemos desarrollar.

El régimen de la responsabilidad civil de los administradores constituye uno de los cambios más significativos introducidos dentro del régimen de propiedad horizontal, y no porque bajo el antiguo régimen de propiedad no existiera, sino porque, la ley 675 de 2001, es clara y precisa al establecer, en su artículo 50, un régimen de responsabilidad civil por culpa presunta, en el ejercicio de la función desempeñada, situación que hasta antes del año 2001, no se encontraba tipificada ni muchos menos tenía las implicaciones que hoy día presenta, dentro de la normativa que direcciona la convivencia dentro de las modernas formas de cohabitación social.

Haciendo un estudio sistemático del actual marco jurídico, no queda más que afirmar que dicha inclusión legal corresponde no a un simple capricho del legislador, sino que por el contrario frente al auge de estas nuevas formas de cohabitar, de relacionarse en sociedad, y frente al nivel de responsabilidad que detentaba la dirección de una copropiedad, el legislador vio la imperiosa necesidad de profesionalizar un oficio que hasta ese momento se había ejercido empírica y hasta instintivamente, siendo la administración de los conjuntos una verdadera alternativa para desempleados. Por fortuna la situación está cambiando, y con el paso del tiempo es percibible como en los órganos de dirección de los bienes sometidos a ley 675 de 2001, imperan debidos criterios de selección al momento de escoger el profesional que represente a la propiedad horizontal.

El problema radica, en que a pesar que en la actualidad, los cargos de administración de las copropiedades, son ejercidos por verdaderos profesionales, estos no conocen de primera mano, cuales son las nuevas tendencias del derecho privado, confeccionado por los tribunales judiciales y por la moderna doctrina internacional. Esta es una labor que de primera instancia tenemos los profesionales del derecho y en la medida en que tanto administración y abogado, se constituyen en un verdadero equipo, sea este el momento para presentarles cuales son los parámetros actuales de la máxima diligencia requerida al momento de administrar la copropiedad.

\section{El análisis de la normativa}

Las novedades más notables introducidas por la legislación se refieren, básicamente, a tres elementos.

A la ampliación de las estructuras de imputación. 


\section{REVISTA VIRTUAL VIA INVENIENDI ET IUDICANDI \\ "CAMINO DEL HALLAZGO Y DEL JUICIO" \\ http://viei.usta.edu.co/ E-MAIL: revistainveniendi@usantotomas.edu.co}

A la transformación del concepto de diligencia.

En el régimen de propiedad horizontal anterior (leyes 182 de $1948^{5}$, ley 16 de $1985^{6}$ y la ley 428 de $1998^{7}$ ), no consagraba en ninguno de sus cuerpos normativos expresamente, bajo qué criterios de imputación o circunstancias debía responder civilmente el administrador o representante legal de las copropiedades, en el caso en que terceros, habitantes o propietarios sufrieran daños ocurridos al interior de las mismas, teniendo que acudir en su momento al art. 2341 C.c., ${ }^{8}$ En la actualidad, el nuevo cuerpo legal (ley 675 de 2001), ha extendido y acrecentado los niveles de responsabilidad que le asisten al representante legal de la copropiedad excluyendo la posibilidad de aplicar la clausula general de reparación en mención. La nueva norma consagra:

"Art. 50. Los administradores responderán por los perjuicios que por dolo, culpa leve o grave, ocasionen a la persona jurídica, a los propietarios o a terceros. Se presumirá la culpa leve del administrador en los casos de incumplimiento o extralimitación de sus funciones, violación de la ley o del reglamento de propiedad horizontal".

Nótese entonces, como ya no solo los administradores responden por, un delito o culpa que cometan sino que además, le es exigible, la diferente y graduación de la culpa, con el agravante que en aquellos casos de incumplimiento o extralimitación de sus funciones (legales, reglamentarias o mandatarias) se consagra una presunción de hecho negativa, en su contra al manifestarse que se supondrá su responsabilidad ante los actos dañosos.

De lo anterior se pueden extraer tres conclusiones:

Que la profesión del administrador está sometida en su ejercicio a altos niveles de diligencia posible. Haciendo más gravosa la situación que el régimen de responsabilidad exigible a encargos de similar naturaleza, como vendrían siendo los que se regulan por el Contrato de Mandato, en cuyo caso al tenor del art. 2155 el mandatario responde hasta la culpa leve en el cumplimiento de encargo. Pero nótese que dicha norma, no presupone graduación alguna lo que si sucede con el cargo del administrador según el art. 50 de la ley 675 de 2001. Situación que no es equiparable a profesión liberal alguna, ya que no existe en la actualidad referencia sobre una consagración legal similar, salvo en lo que

\footnotetext{
${ }^{5}$ De Diciembre 29 de 1948, Sobre régimen de la propiedad de pisos y departamentos de un mismo edificio.

${ }^{6}$ LEY 16 DE 1985. Por la cual se modifica la Ley 182 de 1948, sobre propiedad horizontal

${ }^{7}$ LEY 428 DE 1998. Por la cual se adiciona y reglamenta lo relacionado con las unidades inmobiliarias cerradas sometidas al régimen de propiedad.

${ }^{8}$ ART. 2341.-El que ha cometido un delito o culpa, que ha inferido daño a otro, es obligado a la indemnización, sin perjuicio de la pena principal que la ley imponga por la culpa o el delito cometido.
} 


\section{REVISTA VIRTUAL VIA INVENIENDI ET IUDICANDI \\ "CAMINO DEL HALLAZGO Y DEL JUICIO" \\ http://viei.usta.edu.co/ E-MAIL: revistainveniendi@usantotomas.edu.co}

corresponde a los administradores de las sociedades mercantiles, el art. $200^{9}$ del Código de Comercio, modificado por el art. 24 de la Ley 222 de 1995, así lo consagra.

En Colombia, al interior del régimen de responsabilidad civil subjetiva existen dos clases, una por culpa probada ${ }^{10}$ y otra por culpa presunta. El segundo el exigible a los administradores, tiene por principal característica que a pesar que la responsabilidad sigue fundándose en la culpa, ésta se presume contra el demandado y donde el actor (la víctima) está exonerado de probar la culpa, pero si el perjuicio y nexo causal. Lo anterior se materializa en que, en el momento en el que suceda un daño, bastará a la víctima con demostrar el daño y que el mismo es imputable al administrador, correspondiéndole la carga de la prueba, no al dañado sino al profesional, eximiéndose de su responsabilidad con causales muy concretas que van desde la prueba negativa de la ausencia de culpa, esto es demostrando que se actuó con prudencia y diligencia en el ejercicio del cargo, tanto en aquellos daños que sean imputables al administrador por una acción u omisión directa, o por actos de terceros como sería el caso del daño producido por empleados que estén a su cargo, hasta los eximentes por causa ajena (culpa exclusiva de la víctima, hecho de un tercero, fuerza mayor y caso fortuito), lo que hace que en la práctica los administradores de las propiedades horizontales no tengan una tarea fácil al momento de identificar eximentes de responsabilidad.

3- Todo daño ocurrido al interior de una copropiedad y cuya causa imputable sea atribuible al administrador por omisión o extralimitación conlleva como mínimo un incumplimiento de las obligaciones o funciones que son de su esencia. Así las cosas, por más leve o mínima que sea la falta, frente a la presunción de su culpa, siempre estará implícita la posibilidad del resarcimiento de perjuicios causados no solo a los propietarios de la unidad que administra sino a terceros (visitantes) con el agravante que siempre será el administrador quien tendrá la carga de la prueba de la empleada debida diligencia y cuidado.

No quiere decir lo anterior, que cada vez, que un propietario, residente o un tercero, alegue un perjuicio ocasionado por la copropiedad, tenga siempre que responder ante la copropiedad o ante el mismo tercero, por tanto es importante precisar, que la responsabilidad de los administradores siempre se verá comprometida en el evento en el que no se cumplan los deberes consagrados en el mandato, en el contrato laboral, en el reglamento de copropiedad, o en la ley, lo que nos conlleva a afirmar que poco o nada importa la naturaleza jurídica de la vinculación del administrador y la copropiedad, lo

\footnotetext{
${ }^{9}$ Los administradores responderán solidaria e ilimitadamente de los perjuicios que por dolo o culpa ocasionen a la sociedad, a los socios o a terceros. No estarán sujetos a dicha responsabilidad, quienes no hayan tenido conocimiento de la acción u omisión o hayan votado en contra, siempre y cuando no la ejecuten. En los casos de incumplimiento o extralimitación de sus funciones, violación de la ley o de los estatutos, se presumirá la culpa del administrador.

${ }^{10}$ El actor debe probar la culpa del demandado, el perjuicio y la relación de causalidad y donde la carga de la prueba la tiene el actor.
} 


\section{REVISTA VIRTUAL VIA INVENIENDI ET IUDICANDI \\ "CAMINO DEL HALLAZGO Y DEL JUICIO" \\ http://viei.usta.edu.co/ E-MAIL: revistainveniendi@usantotomas.edu.co}

realmente importante consiste en determinar si el daño se causa producto de un comportamiento culpable o no (mediante la prueba de diligencia y cuidado o de los eximentes de causa ajena) frente a las obligaciones no acatadas o cumplidas por parte del administrador. En otras palabras, el administrador responderá civilmente frente a la copropiedad y a terceros por los daños que se causen con ocasión al ejercicio indebido de su cargo ya sea por acción u omisión de las obligaciones y deberes que le impone directamente el consejo de administración, la ley, o su vinculación jurídica contractual.

Precisado lo anterior, es importante clarificar algo que se ha sugerido, a lo largo de todas estas líneas y es que sin importar si el administrador cumple o no sus obligaciones inherentes al cargo, en el evento en el que se logre identificar que existe una conducta cuando mínima culposa por parte de los órganos de representación y gestión de la copropiedad, que da lugar a la ocurrencia de un daño, y que el mismo permite la constatación de un nexo de causalidad, la responsabilidad de la propiedad horizontal siempre se verá comprometida, ajena a que la copropiedad pueda repetir o incluso llamar en garantía al administrador en el evento en el que se adecue la conducta a lo anteriormente esbozado. O desde el extremo de la víctima la posibilidad que siempre tendrá de ir no sólo contra la copropiedad sino contra la persona de quien la administra en un juicio.

En suma, para poder determinar si el daño es imputable al administrador este deberá ser:

Producto de una conducta desarrollada activa u omisiva en el ejercicio de sus funciones Que el hecho generador del daño, sea producto de una conducta culposa o dolosa de su parte. Aunque este último se presume, y la culpa debe ser leve o grave, pues no responde por culpa levísima según el art 50 de la ley 675.

Para poder determinar si la conducta que se le imputa al administrador es culpable o no, necesariamente es prioritario determinar si el representante ha obrado de acuerdo al mandato de los deberes jurídicos impuestos, puesto que en definitiva la conducta culposa es aquella que incumple la ley, el reglamento de copropiedad o en el contrato (laboral o de mandato). Sin embargo la mencionada responsabilidad no siempre se origina por actuaciones, sino por contrario esta también se puede presentar, en el caso de la omisión o abstención que se produzcan frente al cumplimiento de las funciones legales y reglamentarias.

Las omisiones por tanto también pueden comprometer, la responsabilidad de los sujetos de derecho, y por consiguiente de aquel administrador si de haber realizado la acción omitida, el daño no se hubiera producido siempre y cuando no exista causa que la justifique. Por tanto, las omisiones en el cumplimiento de las funciones bien pueden constituir un comportamiento ilícito generado de responsabilidad. 


\section{REVISTA VIRTUAL VIA INVENIENDI ET IUDICANDI \\ "CAMINO DEL HALLAZGO Y DEL JUICIO" \\ http://viei.usta.edu.co/ E-MAIL: revistainveniendi@usantotomas.edu.co}

¿Pero qué es lo que ocurre, cuando el acto, el acuerdo o la decisión lesiva, el hecho dañoso, es directamente producido por el administrador?

La cuestión es clara, y así lo pretende clarificar la ley, el administrador responderá por sus propios actos, porque son ellos quienes han incurrido en culpa, o en su caso, en dolo o en abuso del derecho, dependiendo de la situación. Mas esa responsabilidad se traslada directamente al consejo de administración que por lo general es quien siempre coopta y nombra a su delegado y representante, aun cuando directamente en el seno del consejo de administración no se haya producido la comisión del acto generador de la responsabilidad.

Aquí se hace presente lo que la doctrina reconoce como la culpa in eligendo y la culpa in vigilando, la cual opera frente al criterio de elección y de vigilancia frente a quien se contrata, en este caso el dominus (consejo de administración) responderá de manera incondicional, por la falta cometida por su representante.

Ya lo reconoce DIEZ PICAZO ${ }^{11}$, afirmando "quien pone en marcha un mecanismo representativo y se beneficia con su utilización debe asumir los riesgos que de ello se sigan (ubi commodu ibi et incommodum), criterio que a juicio propio generará responsabilidad no sólo frente a los actos desarrollados por el administrador, sino también frente a los casos en los cuales se causan daños a propietarios, residentes y terceros por parte de los empleados contratados por la administración.

Expuesta así la determinación de la responsabilidad de los administradores, en ejercicio o con ocasión de sus funciones, la copropiedad puede sufrir perjuicios por sus conductas negligentes y culposas, la labor entonces radica en emprender acciones, que nos permitan adoptar conductas preventivas y cautelosas, frente a eventuales daños, por tanto es necesario entrar a hacer claridad frente a conceptos como diligencia y culpa.

La culpa ha sido entendida como la no previsión de lo que hubiese podido preverse y evitarse. Los Hermanos MAZEAUD ${ }^{12}$ señalan que: "La culpa es un error tal de conducta, que no se habría cometido por una persona cuidadosa, situada en las mismas circunstancias 'externas' que el demandado". Nuestro Código Civil exige el requisito que se comenta (entiéndase aquí culpa) en los artículos 1.604, 2.341 y 2.356 para los fines de estructuración de la responsabilidad civil.

También es definida por el estatuto penal así:

\footnotetext{
${ }^{11}$ Diez Picazo, L., y Gullon Ballesteros, A., "Sistema de Derecho civil", vol. II (Tecnos, Madrid, 1992), pág. 220.

${ }_{12}$ MAZEAUD, Henry, León y Jean. "Lecciones de Derecho Civil -La responsabilidad Civil, Los cuasicontratos-" (Jurídicas Europa América, Buenos Aires, 1980), pág. 123.
} 


\section{REVISTA VIRTUAL VIA INVENIENDI ET IUDICANDI \\ "CAMINO DEL HALLAZGO Y DEL JUICIO" \\ http://viei.usta.edu.co/ E-MAIL: revistainveniendi@usantotomas.edu.co}

"ART. 23. CULPA. La conducta es culposa cuando el resultado típico es producto de la infracción al deber objetivo de cuidado y el agente debió haberlo previsto por ser previsible, o habiéndolo previsto, confió en poder evitarlo".

Es innegable que cuando se habla o cuando se está frente a la materia de culpa, aparece el concepto de diligencia, como la antítesis de la misma, de tal forma que puede llegar a concluirse que aquel que actúa con culpa es porque sin duda, no actuó bajo los parámetros de la debida diligencia.

El gran cuestionamiento que surge, es qué se debe entender por diligencia, y si ésta se ha transformado, de igual forma como lo han hecho las demás instituciones que regulan el derecho de daños. Frente a tal cuestionamiento no queda otra respuesta que aceptar que dicho concepto hoy día dista bastante de lo que en otrora fue para los romanos, quienes fueron los primeros que se aventuraron en definirla (al igual que cientos de instituciones que hoy regulan el derecho no solo latino sino de tradición sajona y bávara).

Nuestro código civil, en múltiples normas cita, al momento de establecer la diligencia debida, las llamadas por la doctrina cláusulas válvula (las cuales debido a su abstracción en la definición, han generado y suscitado múltiples interpretaciones y enfrentamientos judiciales y doctrinales), es entonces común encontrar, epígrafes como la diligencia exigible es la que emplearía un hombre normal de negocios, de igual forma se hace alusión al buen padre de familia.

Y conforme a lo anterior volvemos a la complejidad de esos conceptos abstractos o válvulas generales del ordenamiento; y nos preguntamos ¿Qué comprende la diligencia de un buen padre de familia o del hombre normal de negocios?

La figura del bonus, diligens paterfamilias, expresión que en su origen romano es sinónimo no de padre de familia, sino de hombre sui iuris, de persona o sujeto de derecho, se ha incorporado a la tradición jurídica latina, como metro tradicional del esfuerzo diligente. El buen padre de familia aparecía mencionado en las fuentes jurídicas de la edad republicana (CICERON, CATON, VARRON) como cuidadoso jefe de explotación domestica rural. Pronto esta figura tocó los confines del derecho de obligaciones, y el amor a la construcción y generalización de épocas posteriores lo convirtió en metro universal de culpa. ${ }^{13}$

La diligencia señalada en la obligación, la que corresponde a un buen padre de familia, se trata de un canon sustentado en la "accesibilidad". Es la diligencia a la que puede acceder toda persona normal. Es toda aquella diligencia que guarda el hombre medio, sin que

\footnotetext{
${ }^{13}$ Para ver mas, JoRdAnO FragA, F., "La responsabilidad contractual" (Civitas, Madrid, 1987) pág. 141 Y Ss.
} 


\section{REVISTA VIRTUAL VIA INVENIENDI ET IUDICANDI \\ "CAMINO DEL HALLAZGO Y DEL JUICIO" \\ http://viei.usta.edu.co/ E-MAIL: revistainveniendi@usantotomas.edu.co}

deba ser exigible una diligencia extraordinaria. En el ámbito de la actividad empresarial y profesional, esto se traduciría en la aplicación de un principio de proporcionalidad, sin el cual el deber de diligencia tiene su límite allí donde exista una desproporción apreciable entre el coste de adopción de determinadas medidas de prevención y la probabilidad de que se produzca un daño de alcance relevante ${ }^{14}$. Es decir, el complejo de cuidados y cautelas, el comportamiento debido por el deudor, no se determina con arreglo a sus aptitudes personales, sino con arreglo a un modelo externo a la persona del deudor. Además como queda visto, la diligencia es un criterio de valoración de conductas relativo, conmiserado a la naturaleza de la actividad de que se trate.

De tal forma que cuando estamos frente a la labor que desempeñan los administradores en ejercicio de sus funciones, se podrá exigir una mayor diligencia en sus conducta ejecutadas, ya que estaremos frente al caso de un patrón de conocimiento calificado y experto y por tanto el grado de reproche exigible será mayor que la diligencia empleada entre dos novatos ciudadanos que entablan relaciones negociales. En estos casos la diligencia del buen padre de familia aplicable al comportamiento de los administradores, en realidad expresa, la diligencia de un sujeto normalmente cuidadoso en el ámbito de su actividad $^{15}$.

Al respecto hoy por hoy se afirma, que la elasticidad de la fórmula del buen padre de familia, lejos de ser un inconveniente, se convierte en su mayor valor, pues le permite ser simultáneamente modelo de conducta del pequeño agricultor y de un profesional técnico altamente calificado ${ }^{16}$.

Hasta aquí es necesario entonces entrar a estudiar, que comprende el alcance del art. 50 de la ley 675 de 2001, para esto es imperioso entrar a estudiar lo que se entiende por dolo o culpa grave, y leve ${ }^{17}$.

a- El dolo o fraude: Significa engaño, o simulación. Astucia, trampa, maquinación o artificio que se emplea para engañar a otro. Es la mala intención. Es "toda aserción de lo que es falso o disimulación de lo verdadero (...). Por regla general, el dolo no se presume, sino que quien lo alega debe probarlo. En suma, se presenta dolo en el "acto ilícito ejecutado a sabiendas y con intención de dañar (...) la persona".

b- La culpa grave o lata: Implica la impericia, negligencia o imprudencia del agente, no su mala intención o querer doloso. Consiste en "no tomar las más elementales precauciones, en no hacer lo que todos considerarían necesario en casos análogos", o en no

\footnotetext{
${ }^{14}$ Reglero Campos, F., "Lecciones de Responsabilidad civil" (Aranzadi, Navarra, 2002), pág. 63.

${ }^{15}$ Jordano Fraga F, op cit., pág. 122, LaCRuz Berdejo, J, L., "Elementos de derecho civil", Parte general, teoría general del contrato, tomo II, vol. I (Bosch, Barcelona, 1994), pág. 97 y ss.

16 JoRDANO FRAGA F, op cit., pág. 134.

17 A pesar que el art. 1604 del Código civil habla de la levísima, el estudio de la culpa leve subsume la levísima, por tanto consideramos que no es necesario su abordaje.
} 


\section{REVISTA VIRTUAL VIA INVENIENDI ET IUDICANDI \\ "CAMINO DEL HALLAZGO Y DEL JUICIO" \\ http://viei.usta.edu.co/ E-MAIL: revistainveniendi@usantotomas.edu.co}

emplear la diligencia que todos los hombres pondrían en ello. A su vez el art. 63 del C.c. consagra:

"Art. 63: Culpa grave, negligencia grave, culpa lata, es la que consiste en no manejar los negocios ajenos con aquel cuidado que aun las personas negligentes o de poca prudencia suelen emplear en sus negocios propios, esta culpa en materias civiles equivale a dolo...".

Uno de los elementos de la culpa grave es la imputabilidad, o sea que el hecho pueda ser atribuido a una persona, en cuanto tiene plena conciencia del acto que ejecuta. La culpa también se debe "individualizar", esto es, "juzgarla de acuerdo con el estado general de quien ha incurrido en ella y con las modalidades del medio circundante", o sea teniendo en cuenta las circunstancias concretas de tiempo, modo y lugar en que ocurrió el hecho.

En síntesis, la culpa lata o grave se presenta "cuando no se emplea la diligencia que todos los hombres, aun los menos cuidadosos, suelen poner en sus cosas o en sus negocios". Es "el descuido o desprecio absoluto en la adopción de las precauciones más elementales para evitar un mal o daño; que en el Derecho romano se caracterizaba por la negligencia en que no -sic- incurría el administrador más torpe; como interrumpir una prescripción estando presente, dejar el dinero al alcance de extraños, romper un documento sin haberlo leído, no hacer ninguna reparación en los edificios necesitados de ellas, ni las labores que las cosechas precisen".

c- La culpa leve: "La negligencia en que incurre un buen padre de familia". Esta negligencia no es endilgable a las personas, del común, por denominarlas de algunas, forma, ya que es una negligencia que para la mayoría de los ordenamiento civiles es tolerable, no obstante, nótese como ésta incluso es exigible expresamente a los administradores.

En los últimos años, se ha venido dando un aumento progresivo de la diligencia exigible, y esto sin duda se ha convertido en algo difícil de superar. Esto ha conllevado a que los jueces en la actualidad, eleven el listón de la diligencia hasta el punto de afirmar que si ha existido daño, será porque no se adoptaron las medidas de diligencia requeridas por el caso $^{18}$. Lo anterior, no ha hecho otra cosa que profundizar la complejidad del establecimiento de esos parámetros de conducta, para medir la diligencia que exija la naturaleza de la obligación y que corresponda a las circunstancias de las personas, del tiempo y del lugar.

2. Como quedó demostrado, la ley 675 de 2001, cambia el régimen de responsabilidad aplicable a las conductas reprochables a los administradores en donde el sistema exigible

\footnotetext{
18 Para ver mas, YZQuIERdo TolsadA, M., "Sistema de responsabilidad civil, contractual y extracontractual” (Dykinson, Madrid, 2001), pág. 222 y ss.
} 


\section{REVISTA VIRTUAL VIA INVENIENDI ET IUDICANDI \\ "CAMINO DEL HALLAZGO Y DEL JUICIO" \\ http://viei.usta.edu.co/ E-MAIL: revistainveniendi@usantotomas.edu.co}

es el de culpa presunta, de tal forma que éste hoy responde por los perjuicios que contractual o extracontractualmente, ocasionen no solo a los miembros de la copropiedad sino a terceros.

Situación que en la práctica significa, que basta con que la víctima, alegue la existencia de un daño, demostrando la relación de causalidad, o sea que el daño se generó por como la indebida aplicación de los deberes contractuales, legales y reglamentarios por parte del administrador, y este tendrá la carga de prueba, excusándose de tal responsabilidad mediante, la demostración del empleo de la diligencia debida o por la existencia de causa ajena (la existencia de fuerza mayor o caso fortuito, hecho o culpa de la víctima del daño o de un extraño).

Por regla general, la responsabilidad civil en Colombia es subjetiva, o sea que cabe entrar a analizar si la conducta se realizó con dolo (o intención) o con culpa (imprudencia, negligencia o impericia) y su principal característica radica en que el que alegue el daño debe entrar a probar no solo la existencia del mismo, sino todos los elementos que constituyen un hecho culpable, la culpa, el perjuicio propiamente y el nexo de causalidad. Sin embargo, por excepción la responsabilidad será por culpa presunta, como ocurre, entre otros, en los siguientes casos:

Responsabilidad por el hecho ajeno.

Responsabilidad de padres de familia, guardadores, empleadores, profesores, artesanos (todos aquellos que tienen subordinación).

Responsabilidad por la ruina de un edificio y por las cosas que se arrojan o caen de una edificación.

Responsabilidad por el hecho de los animales domésticos.

Los administradores de las sociedades mercantiles y de las copropiedades.

El administrador podrá librarse de su responsabilidad mediante la prueba negativa de la ausencia de culpa, demostrando que se actuó con prudencia y diligencia en todas aquellas actividades relacionadas con la ocurrencia del acto dañoso o buscando lugar a la existencia de los eximentes de responsabilidad por causa ajena, sobre los que dedicaremos las siguientes páginas, medidas capaces de descartar cualquier hipótesis de responsabilidad por acarrear ellas la completa eliminación del nexo causal.

Estudio sobre los eximentes de responsabilidad 


\section{REVISTA VIRTUAL VIA INVENIENDI ET IUDICANDI \\ "CAMINO DEL HALLAZGO Y DEL JUICIO" \\ http://viei.usta.edu.co/ E-MAIL: revistainveniendi@usantotomas.edu.co}

El caso fortuito y la Fuerza mayor. Se llama fuerza mayor o caso fortuito el imprevisto a que no es posible resistir, como un naufragio, un terremoto, el apresamiento de enemigos, los autos de autoridad ejercidos por el funcionario público etc. Son dos los elementos que caracterizan estos casos, la imprevisibilidad y la irresistibilidad.

La diferencia radica, en que el caso fortuito concierne a hechos provenientes del hombre, en cambio la fuerza mayor toca con hechos producidos por la naturaleza. De tal forma que un corto circuito sería un caso fortuito, y un incendio ocasionado por un rayo seria fuerza mayor.

Desde luego, son consideraciones que deben hacerse teniendo en cuenta el acontecimiento de que se trata, pero en general, se estima que un evento es imprevisible cuando se configura un fenómeno raro, súbito, repentino, al paso que lo irresistible implica aquello que domina toda resistencia normal y que resulta imposible de ser contrarrestado. Por ende en tanto, que sea posible prever la realización de un hecho susceptible de oponerse al hecho causante del daño, y que este evento puede evitarse con diligencias y cuidado no hay caso fortuito ni fuerza mayor. En este caso si el administrador quisiera alegar uno de estos o parecidos acontecimientos pretendiendo librarse del cumplimiento de su obligación, debe no solo probar el hecho, sino demostrar también las circunstancias que excluyan su culpa ${ }^{19}$.

EL HECHO DE UN TERCERO. Por tercero se entiende la persona que no tiene ningún vinculo con las partes involucradas en un asunto de responsabilidad civil, en consecuencia es aquella persona que carece de toda relación, contractual o legal, con el demandante y el demandado, y por consiguiente no ostenta la calidad de subordinado, agente, dependiente, auxiliar, representante, sustituto, hijo, pupilo etc.

La jurisprudencia colombiana, siguiendo en este punto la jurisprudencia francesa, ha considerado que para el hecho del tercero interrumpa el vinculo causal, son necesarios que varios requisitos cuya presencia objetiva en cada caso es la que permite concluir que no obstante las apariencias que se desprenden de la actuación atribuible al demandado, ciertamente sus consecuencias no le pertenecen por ser otro el verdadero y único causante del agravio.

Reduciéndose lo anterior a:

Que el hecho del tercero le sea ajeno al agente, o responsable presunto.

El hecho haya sido la causa exclusiva del daño.

\footnotetext{
${ }^{19}$ Art. $1604 \ldots .$. La prueba de la diligencia o cuidado incumbe al que ha debido emplearlo, la prueba del caso fortuito al que lo alega.
} 


\section{REVISTA VIRTUAL VIA INVENIENDI ET IUDICANDI \\ "CAMINO DEL HALLAZGO Y DEL JUICIO" \\ http://viei.usta.edu.co/ E-MAIL: revistainveniendi@usantotomas.edu.co}

Dicho en otras palabras, el hecho en cuestión tendría que ser de tal naturaleza, que el hecho del tercero, fue imprevisible e irresistible, o sea que existe una total ausencia de culpa de los extremos.

Hecho de la propia víctima.

Es aquel hecho que es considerado como causa única y exclusiva del daño, y por tanto se interrumpe el vínculo causal, y por tanto el demandado, o llamado a responder debe salir indemne de las imputaciones que se le formulan, por verse comprometida en exclusiva la culpa de la víctima.

3. Visto lo anterior, y frente a la taxatividad existente en la ley en los casos de eximentes de responsabilidad subjetiva por culpa presunta, no podemos ocultar la realidad en la que se encuentra el administrador de la copropiedad en Colombia, lo que conlleva sin duda, a que en el ejercicio de su actividad, se tomen todas las medidas del caso, para que en el evento en el que se le impute responsabilidad, pueda salir airoso de tal enjuiciamiento.

Pero qué se puede hacer entonces, para que el administrador pueda eximirse de eventuales imputaciones civiles por responsabilidad?

Tal y como están las cosas, no solo por mandato de la ley sino por las propias dificultades que presenta el ejercicio de una profesión donde hay que mediar entre conflictos de vecinos, (siendo sicólogos), administrar y cobrar dinero (siendo recaudadores, y porque no chepitos), velar y cuidar por los bienes comunes (ejerciendo la labor de depositarios o guardias sabuesos), oír y escuchar y además soportar a personas sin mayores oficios $u$ ocupaciones, (consejeros, y hasta terapeutas familiares), no queda más que afirmar que necesariamente, siempre habrá un responsable de todas las desavenencias, tanto personales, familiares, sociales y económicas no solo de las familias sino de los problemas que normalmente suceden dentro de una organización social tan grande y compleja como es la que se encuentra comuneramente dentro de la copropiedad.

Además, no se puede olvidar que siempre estará expuesto el administrador que frente a cualquier demanda que se presente en contra de una copropiedad, esta pueda hacer uso de una figura procesal que se llama el litisconsorcio, aun cuando ya se haya desvinculado con la copropiedad.

El litisconsorcio es un concepto referido a la pluralidad de sujetos participantes en el proceso jurisdiccional integrando una o varias partes procesales, por activa y/o por pasiva. El tratadista colombiano Jairo Parra Quijano manifiesta: "Esta palabra traduce o denota la presencia de varias personas en el proceso, unidas en determinada situación. Se podría 


\section{REVISTA VIRTUAL VIA INVENIENDI ET IUDICANDI \\ "CAMINO DEL HALLAZGO Y DEL JUICIO" \\ http://viei.usta.edu.co/ E-MAIL: revistainveniendi@usantotomas.edu.co}

afirmar que todas las legislaciones y doctrinas admiten la existencia de varias personas en la situación de demandante o demandado, o en ambas calidades".

No obstante, siempre se buscará un responsable, se ha considerado que ante tan desproporción tanto de las situaciones sociales descritas como de la responsabilidad civil existente por parte de los administradores (por la presunción de su culpa), una de las medidas, por medio de las cuales puedan blindarse y protegerse de un eventual reproche de sus conductas, consiste en la prevención y adopción de medidas en todo su ejercicio profesional (aparte evidentemente del cumplimiento irrestricto de la legislación que regula la propiedad horizontal ${ }^{20}$ ), las cuales sin duda darán lugar a que ocurrido eventualmente un hecho, se pueda demostrar la diligencia y cuidado empleado o en su defecto trasladar la responsabilidad a la victima por ser ella quien no empleó las medidas tendientes a evitar la producción del mismo, causales que serían las que normalmente se podrían presentar con más frecuencia en un eventual juicio.

Recordemos que el nuevo derecho resarcitorio se ampara en la preferencia de prevenir que curar, de ahí que en la actualidad y sobretodo en el ámbito internacional la moderna doctrina civilista ha destinado una abundante y rigurosa producción a predicar para dicha institución una función preventiva del daño ${ }^{21}$.

A continuación se presenta un catálogo de medidas que deben ser tenidas en cuentas y que demostrarían un correcto y adecuado comportamiento por parte de los administradores y representantes de la copropiedad. Dicha metodología solo se emplea con miras a presentar una visión práctica e ilustrativa y como toda enumeración es susceptible de mejoramiento.

\section{RECOMENDACIONES.}

Efectuar un análisis de riesgo, en los puntos o lugares neurálgicos, a la propensión u ocurrencia de siniestros. Una vez se identifiquen los mismos se debe proceder a instalar avisos de advertencia, frente a los riesgos a los que potencialmente están expuestos los residentes, propietarios y terceros. Por ejemplo en las zonas de plantas y reguladores eléctricos, instalar avisos preventivos sobre la posibilidad de choques eléctricos. Frente a la evaluación de riesgos se pueden encontrar también por ejemplo debilidades en muros o rejas, situación esta que siempre debe ser informada a los encargados de seguridad.

\footnotetext{
${ }^{20}$ Ley 675 de 2001, por medio de la cual se expide el Régimen de Propiedad Horizontal, Ley 746 de Julio 19 de 2002 " por la cual se regula la tenencia y registro de perros potencialmente peligrosos" , el decreto 4950 de diciembre 27 de 2007 y la circular externa 01 de 2008 de la superintendencia de vigilancia y seguridad privada. La ley 1209 de 2008, por medio de la cual se establecen normas de seguridad en piscinas.

${ }^{21}$ LLAMAS PomBo, E., "La tutela inhibitoria del daño" (Civitas, Madrid, 2004).
} 


\section{REVISTA VIRTUAL VIA INVENIENDI ET IUDICANDI \\ "CAMINO DEL HALLAZGO Y DEL JUICIO" \\ http://viei.usta.edu.co/ E-MAIL: revistainveniendi@usantotomas.edu.co}

Es necesario que se adopten todas las medidas, correspondientes a la transmisión de la información, ya como un derecho que tienen los residentes y propietarios, y como una obligación que la diligencia les impone a los administradores. Al cumplir con la esencia de transmitir la información frente a la ocurrencia de siniestro se podrá determinar una inversión de la responsabilidad, con la posibilidad de configurar la causal culpa exclusiva de la víctima, como vendría siendo el caso en el que se están limpiando los pisos y se instalan avisos que advierten dicha circunstancia y la posibilidad inminente de caídas, y no obstante el transeúnte hace caso omiso de las advertencias.

En las zonas comunes tales como piscinas, saunas, canchas, salones sociales, es necesario instalar en lugares de fácil acceso público, las normas que consagren su uso y qué no está permitido en los mismos.

Contratar con profesionales, el mantenimiento y cuidado de las zonas húmedas de los conjuntos, (ya que éstas son muy propensas a virus y epidemias que pueden sufrir poblaciones frágiles como lo son los niños y mayores adultos quienes son los visitantes frecuentes de las mismas) y de todas aquellas.

Es necesario un detallado y cíclico análisis sobre el estado de las instalaciones comunes, de tal forma que es conveniente, estar cambiando o refaccionando, las lozas defectuosas, el machihembre que se encuentre despegado.

Cada vez, que se realicen contrataciones de que impliquen cantidades considerables de dinero es necesario que se informe y autorice POR ESCRITO, por parte del consejo de administración las mismas.

Tener en cuenta las fechas de vencimiento de las pólizas colectivas, de sismo resistencia y de incendio y renovarlas o contratarlas en los tiempos adecuados.

Al momento de contratar personal, es conveniente delegar esta función a una empresa especializada en el ramo, ya que así se estará desplazando el riesgo por culpa in eligiendo, ya que serán estos profesionales, los que se encargaran de suministrar personal idóneo y calificado.

Hacer revisiones periódicas sobre el cumplimiento de las funciones de los empleados que están bajo subordinación, de tal forma que se podrán detectar acciones indebidas de los mismos o actos que constituyan hechos culposos. Lo anterior servirá como una prevención de una eventual culpa in vigilando. 


\section{REVISTA VIRTUAL VIA INVENIENDI ET IUDICANDI \\ "CAMINO DEL HALLAZGO Y DEL JUICIO" \\ http://viei.usta.edu.co/ E-MAIL: revistainveniendi@usantotomas.edu.co}

No es aconsejable tener porteros o los llamados conserjes ejerciendo labores de vigilancia, porque es la misma ley la que lo prohíbe y además en el evento en el que se causen daños a copropietarios o terceros, en el caso de contar con una compañía de seguridad contratada, esta es la que tendrá que salir a la defensa de la conducta que se le imputa a la copropiedad.

No permitir ni patrocinar la contratación irregular de personal, en la copropiedad, ya que frente a eventuales demandas, la responsabilidad del administrador será más que notoria. Un ejemplo son los famosos contratos de prestación de servicios de jardineros, aseadoras etc, donde la relación laboral es más que evidente.

No contratar a los famosos toderos, para la realización de las diferentes labores de las copropiedades, es pertinente contratar especialistas para la realización de estas tareas.

Es conveniente, que una vez, los residentes o propietarios se constituyan en mora, y si esta asciende a 3 meses o más, debe otorgarse poder al abogado, para que se inicien los cobros pertinentes, y así se evita que cualquier copropietario pueda acusar de negligente el debido recaudo de los dineros sociales, y además no se constituya la conducta del administrador como una conducta indebida, según la ley 675 de 2001 y el reglamento interno.

El abogado, debe ser considerado como miembro o parte fundamental de una adecuada y calificada administración de una copropiedad, ya que también, al tener contratados los servicios de éste se evita una eventual falta o daño a la copropiedad o a los residentes, puesto que una vez se le otorgue poder es el responsable del correcto y adecuado ejercicio del encargo (defensa judicial, cobro de cartera etc.)

Por último, no queda más que afirmar que los riesgos de ejercer una administración siempre estarán presentes, lo que se puede hacer es tomar las medidas necesarias para evitar que ocurran contingencias imputables a una indebida dirección de la copropiedad, y esto solo se logra, cuando se tiene conciencia de la labor y responsabilidad que se tiene, cuando se toman las medidas preventivas del caso, cuando se obra con diligencia y cautela y además, cuando se cuenta con una correcta y calificada asesoría jurídica. 


\section{REVISTA VIRTUAL VIA INVENIENDI ET IUDICANDI \\ "CAMINO DEL HALLAZGO Y DEL JUICIO" \\ http://viei.usta.edu.co/ E-MAIL: revistainveniendi@usantotomas.edu.co}

\section{FUENTES BIBLIOGRÁFICAS.}

\section{Sentencias}

- Sentencia de la Corte Constitucional C-318 de mayo 2 de 2002. M.P. Alfredo Tulio Beltrán Sierra.

- Sentencia de la Corte Constitucional T-143 febrero 22 de 2000. M.P. Antonio Barrera Carbonell.

- Sentencia de la Corte Constitucional T-468 de mayo 13 de 2004 M.P. Gerardo Monroy Cabra.

\section{Leyes}

- Ley 182 de 1948 Sobre régimen de la propiedad de pisos y departamentos de un mismo edificio.

- Ley 16 de 1985 Por la cual se modifica la Ley 182 de 1948, sobre propiedad horizontal

- Ley 428 de 1998. Por la cual se adiciona y reglamenta lo relacionado con las unidades inmobiliarias cerradas sometidas al régimen de propiedad.

\section{Libros}

- Diez Picazo, L., y Gullon Ballesteros, A., "Sistema DE DERECHO CIVIL", VOL. II (TECNOS, MADRID, 1992), PÁG. 220.

- Jordano Fraga, F., "La responsabilidad contractual" (Civitas, Madrid, 1987) pág. 141 y ss.

- Lacruz Berdejo, J, L., "Elementos de derecho CiviL", Parte general, teoría GENERAL DEL CONTRATO, TOMO II, VOL. I (BOSCH, BARCELONA, 1994), PÁG. 97 Y SS.

- MAZEAud, Henry, León y Jean. "Lecciones de Derecho Civil -La responsabilidad Civil, Los cuasicontratos-" (Jurídicas Europa América, Buenos Aires, 1980), pág. 123.

- Reglero Campos, F., "Lecciones de Responsabilidad civil" (Aranzadi, Navarra, 2002), pág. 63.

- Yzquierdo Tolsada, M., "Sistema de responsabilidad civil, contractual y extracontractual" (Dykinson, Madrid, 2001), pág. 222 y ss. 